\title{
Os desafios da verticalização urbana no pós-pandemia
}

\author{
ODAIR SENRA - Presidente \\ JORGE BATLOUNI NETO - Vice-presidente Tecnologia e Qualidade \\ Sindicato da Indústria da Construção Civil do Estado de São Paulo - SindusCon-SP
}

\section{INTRODUÇÃOO}

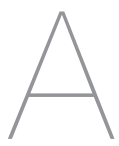

pandemia de Covid-19 abriu uma crise sanitária, econômica, social e política de proporções até então não imaginadas, desde março de 2020, e que ainda deverá se aprofundar nos próximos meses. As consequências se farão sentir por muitos anos, com repercussões que lançam de imediato novos desafios às construtoras e às incorporadoras.

As mudanças em operação na sociedade brasileira revelam decréscimos do emprego e da renda, que afetam drasticamente a demanda imobiliária. No momento em que escrevemos este artigo (em julho de 2020), 87,7 milhões de brasileiros em idade de trabalhar estão sem ocupação, mais do que os 85,9 milhões formalmente trabalhando, de acordo com os dados da Pesquisa Nacional por Amostra de Domicílios Contínua, relativa a maio,do IBGE.

\section{DESAFIOS NO SEGMENTO DE PRÉDIOS RESIDENCIAIS}

Neste cenário, o atendimento daquela parte da demanda por moradia, originada do segmento popular - que compõe a maioria do déficit habitacional -, aumentará sua dependência de programas de governo como o "Minha Casa Minha Vida", ou daquele que deverá sucedê-lo.
No entanto, qualquer que seja a nova arquitetura financeira a ser definida para o atendimento dessa demanda, a escassez dos recursos governamentais para subsidiar a construção de moradias populares deverá persistir.

Portanto, o desafio no segmento da baixa renda será projetar e construir empreendimentos com orçamentos bastante apertados, capazes de suprir minimamente a demanda habitacional. Isso deverá requerer projetos enxutos, eficientes em termos produtivos e bem dimensionados, com sistemas construtivos também mais produtivos e muita gestão.

Já para o segmento de renda média, anteveem-se mudanças. A mais visível é o efeito da expansão do home office sobre os projetos dos futuros empreendimentos imobiliários. Uma parte das famílias de classe média vai demandar imóveis com áreas maiores, dotados de espaços reservados ao teletrabalho com privacidade. Estimativa do IBGE indica que há 8,9 milhões de pessoas trabalhando em suas residências, contra 1,2 milhão há um ano.

A procura por imóveis de áreas maiores, aliás, já começou a ocorrer. A demanda por casas em condomínios fechados, em áreas próximas às capitais de estados, é um fato, ao menos no Rio de Janeiro e em São Paulo. Ou seja, para ter uma área maior, deve-se morar longe do centro. O grande empecilho era o custo e o tempo gasto no transporte. Com o home office, isso está resolvido.

Entretanto, há dois limitadores nesta questão, nos empreendimentos verticais. O primeiro é de ordem financeira. Apartamentos com áreas maiores terão custo mais elevado. As famílias de classe média, dependentes de financiamento imobiliário, continuarão majoritariamente em busca dos imóveis que caibam em seus orçamentos. Muitas não terão como arcar com elevações de preços. Será preciso lançar mão de projetos muito bem arquitetados, com inovações construtivas, produtividade e boa gestão, para ofertar unidades mais amplas e ainda acessiveis a esse segmento. Ou projetar unidades mais versáteis que contenham um espaço adequado ao teletrabalho.

A segunda limitação é imposta pelos Planos Diretores das grandes cidades, que, a exemplo de São Paulo, colocaram restrições ao potencial construtivo dos empreendimentos fora dos eixos de transportes, para tentar adensar nesses eixos e horizontalizar a expansão urbana nas demais regiões. Além disso, criaram coeficientes de aproveitamento para limitar o tamanho das unidades habitacionais, aumentando o adensamento e 
incentivando o uso do transporte coletivo. Isso levou as construtoras e as incorporadoras a investirem em unidades habitacionais de áreas menores, especialmente nos corredores viários. Criar espaços com privacidade para o trabalho remoto nesses empreendimentos será um desafio e tanto.

De qualquer forma, a existência de um escritório dentro de um apartamento será para muitas famílias - e em alguns casos já está sendo - um elemento tão ou até mais relevante do que a localização do imóvel. Dentro do mercado, seguramente haverá uma migração dessas famílias para imóveis com áreas mais amplas, algumas delas não se importando de se mudarem para bairros considerados não tão bem localizados como outros, ou mais distantes.

Também deverá pesar na decisão de mudança a busca por imóveis mais ensolarados e iluminados, em localidades mais silenciosas. Possivelmente, espaços de convívio, como cozinhas e terraços mais amplos, também serão objetos de desejo.

Dependendo de como esse movimento evoluir, a procura por novos terrenos por parte das incorporadoras e construtoras também poderá mudar. Terrenos em bairros antes muito requisitados poderão deixar de sê-lo, enquanto a demanda por outros nos demais bairros aumentará - com reflexos mais adiante nos seus preços.

No limite, a pandemia poderá provocar alguma horizontalização da expansão urbana. Mas, para tanto, outros fatores precisariam acontecer, para que a proximidade às áreas centrais deixe de ser o elemento preponderante na preferência do comprador. Por exemplo, uma ampla expansão da infraestrutura e da oferta de serviços de quali- dade, aliada à elevação da segurança pública - algo difícil de se visualizar no médio prazo, diante da dimensão atingida pela crise social no país nos grandes centros urbanos. Portanto, a horizontalização só teria sentido se essas condições ocorressem. O adensamento vertical continua sendo uma opção urbanística.

Já para o segmento de alta renda, será natural a busca por apartamentos amplos, com espaços para até mais de um escritório. A permanência de um tempo maior dentro da residência levará à oferta de itens que proporcionem todo o conforto possível. E a preferência de localização do imóvel deste segmento deverá continuar sendo em locais nobres.

Outros aspectos ainda devem ser levados em conta. A maior permanência dentro do imóvel residencial valorizará os espaços que anteriormente não eram tão utilizados. Além disso, o consumo de água e energia irá aumentar.

Ante as novas necessidades, o desempenho dos imóveis mais antigos pode não ser satisfatório, no tratamento acústico entre as unidades habitacionais e dentro das mesmas, e no desempenho térmico e lumínico. A busca por imóveis novos de alto padrão poderá levar à oferta de unidades que ofereçam mais do que o mínimo exigido pela NBR 15575 - Norma de Desempenho de Edificações, no que tange aos desempenhos acústico, lumínico e térmico.

Outro aspecto a destacar é a necessidade de se melhorar a conectividade do home office: uma internet rápida e estável, aguardando a chegada do 5G.

Soluções criativas certamente não faltarão. E poderão estar também associadas ao fator geográfico. Por exem- plo, a localização de empreendimentos habitacionais de alto padrão nas proximidades de hospitais de primeira linha e em vizinhanças bem abastecidas de infraestrutura e serviços.

\section{DESAFIOS NO SEGMENTO DE PRÉDIOS COMERCIAIS}

Com relação aos empreendimentos comerciais, pode-se antever uma redução da área ocupada pelas empresas nas lajes corporativas em edifícios de escritórios e espaços de coworking - onde empresas distintas dividem o mesmo espaço, não simultaneamente. $\mathrm{Na}$ medida em que o teletrabalho se consolide no pós-pandemia, o tamanho dos escritórios nesses empreendimentos naturalmente diminuirá. Menos pessoal será requerido presencialmente e se tornará mais comum a utilização de estações de trabalho - mesas, cadeiras e equipamentos despersonalizados, em pontos de trabalho de multiusuários em sistema de rodízio. Amplas salas de reunião deverão encolher ou até desaparecer, em função da proliferação das reuniões virtuais. Ou, se criarem espaços para salas de reunião, que poderão ser utilizados sob demanda.

Essas mudanças também implicarão menos vagas de garagem, melhorando o trânsito, em um benefício inegável para as cidades.

Como se sabe, o mercado para novos empreendimentos de escritórios andou de lado nos últimos anos em função da crise, esboçando mais recentemente uma reação dos edifícios com lajes corporativas, interrompida com a eclosão da pandemia. Hoje, parte dos conjuntos de pequenos escritórios encontra-se vazia, o que poderá levar algumas empresas a se desfazerem dos mesmos. 
Assim, outra consequência possível do aumento da oferta e da diminuição do tamanho das lajes é a redução de seu preço, tornando os escritórios acessíveis a novas empresas ou àquelas que, por alguma razão, necessitem mudar sua localização.

\section{MEDIDAS SANITÁRIAS NOS CANTEIROS}

No que tange à construção propriamente dita, as normas de prevenção à Covid-19 implementadas nos canteiros de obras vieram para ficar por um bom tempo. No Estado de São Paulo, uniram-se nessas ações o SindusCon-SP, a Abrainc (Associação Brasileira de Incorporadoras Imobiliárias), o Secovi-SP (Sindicato da Habitação), o Seconci-SP (Serviço Social da Construção) e o Sintracon-SP (Sindicato dos Trabalhadores nas Indústrias da Construção e do Mobiliário de São Paulo).

Entre as medidas adotadas, estão: medição de temperatura corporal antes do ingresso nos canteiros; uso obrigatório de máscaras; distanciamento na obra e na área de vivência; higienização frequente das mãos, das ferramentas e dos equipamentos de proteção individual, e fornecimento de máscaras para utilização nos canteiros e nos trajetos entre a obra e a residência do trabalhador.

Estas medidas foram tão relevantes que vieram complementar as normas de segurança do trabalho. E justamente a disciplina dos trabalhadores em atenderem às normas de segurança facilitou a introdução das novas medidas protetivas da saúde. Deve-se ressaltar também que o ambiente de construção favorece a não propagação do vírus, pois é na- turalmente arejado e, em grande parte do tempo, com baixa densidade de pessoas.

Estas novas práticas tiveram sua eficácia comprovada por pesquisas semanais feitas pelo SindusCon-SP e pelo Seconci-SP, em maio e junho. Elas mostraram que o percentual de trabalhadores afastados com suspeita de Covid-19 mantinha-se na faixa de $2 \%$, enquanto o de efetivamente contaminados permanecia em $1 \%$.

\section{PRÁTICAS SUSTENTÁVEIS NA CONSTRUÇÃO}

Outro aspecto relevante relativo à construção são as ações pelo incremento de práticas de sustentabilidade, tanto na edificação dos empreendimentos como na sua operação pelos futuros usuários.

Antes da pandemia, boa parte das construtoras já implementava essas práticas, estimulada pela atuação do SindusCon-SP, por meio de seus Comitês de Tecnologia e Qualidade (CTQ) e de Meio Ambiente (Comasp).

Projetos de empreendimentos já são idealizados prevendo racionalização do consumo de água e energia, quando os mesmos estejam em construção e posteriormente em operação. Exigências da Norma de Desempenho de Edificações são atendidas visando ao conforto dos futuros usuários. A construção já é feita com mínima geração de resíduos e os mesmos são separados e devidamente encaminhados ao descarte seguro ou à reciclagem. Materiais que exijam menos impactos ambientais em sua fabricação são utilizados. E, neste momento, um software para que as construtoras possam calcular as emissões de gases de efeito es- tufa durante a construção de empreendimentos está sendo desenvolvido pela entidade, em cooperação com a Agência Internacional de Cooperação da Alemanha e o governo federal.

A pandemia parece ter vindo ao encontro da melhora climática, na medida em que houve sensível redução das emissões de gases de efeito estufa e, consequentemente, da qualidade do ar. Essa melhora, entretanto, não assegura que tais condições permanecerão quando a contaminação pelo coronavírus estiver controlada. Nem arrefece a determinação da indústria da construção de aprofundar as práticas de sustentabilidade, que trazem benefícios ao meio ambiente e aos futuros usuários dos empreendimentos.

Os efeitos das mudanças climáticas ocorridas nos últimos anos ainda estão bastante presentes, como, por exemplo, no aumento da velocidade dos ventos, que exige a construção de empreendimentos imobiliários mais resistentes. Ou, por exemplo, nas enchentes, que aumentam de intensidade a cada ano, requerendo constante preocupação do setor da construção com a devida permeabilização dos solos nas áreas comuns dos empreendimentos.

Consciente das possíveis mudanças que ocorrerão no pós-pandemia, a indústria da construção já tem os meios para enfrentar todos esses novos desafios. E deverá responder à altura, tão logo surjam as condições para uma retomada consistente da economia, e com a expectativa de que a política econômica também encontre soluções para a volta do emprego e da renda aos cidadãos brasileiros, hoje tão afetados pela pandemia. 